\title{
OBESITY NEEDS MORE ATTENTION IN BANGLADESHI PATIENTS WITH CORONAVIRUS DISEASE 2019 (COVID-19)
}

\author{
MD. SHAHED MORSHED ${ }^{1}$, MD. FIROJ HOSSAIN ${ }^{2}$, MD. HABIBUL GHANI $^{3}$
}

Received: 04 December, 2020

Accepted: 25 December, 2020

DOI: https://doi.org/10.3329/bjm.v32i1.51101

In their original article, Islam QT, et al. found that around $50 \%$ of patients with coronavirus disease 2019 (COVID-19) had both hypertension and diabetes mellitus (DM) but obesity was found only in $0.8 \%$ of cases. Though the cut off to define obesity was not mentioned, it seems to be under reported. ${ }^{1}$ As measurement of height and weight may impose extra risk of exposure to physicians, so most of the studies published from Bangladesh did not address obesity. Obesity is associated with several comorbidities that may involve almost every discipline of medical science. Literatures also suggest that obesity is associated with more chance of infection and disease progression with higher mortality from COVID-19.2,3 However, these data are hospital-based. Therefore, we collected and analyzed population data of 164 countries (all required data available) from the website of world health organization and international diabetes federation. 4,5,6 We found that prevalence of obesity and DM were positively correlated with mortality from COVID-19 per million general populations (Figure 1a and 1b). But there was no significant correlation between prevalence of hypertension with mortality rate from COVID-19 ( $\mathrm{r}=$ $-0.07, p=0.39$ ). Linear regression analysis showed that only prevalence of obesity was positively associated with mortality rate $(B=7.14,95 \%$ confidence interval of $B=4.32,9.96 ; \beta=0.37, p<0.001)$. The association of prevalence of $\mathrm{DM}$ was not significant $(\mathrm{B}=5.18,95 \%$

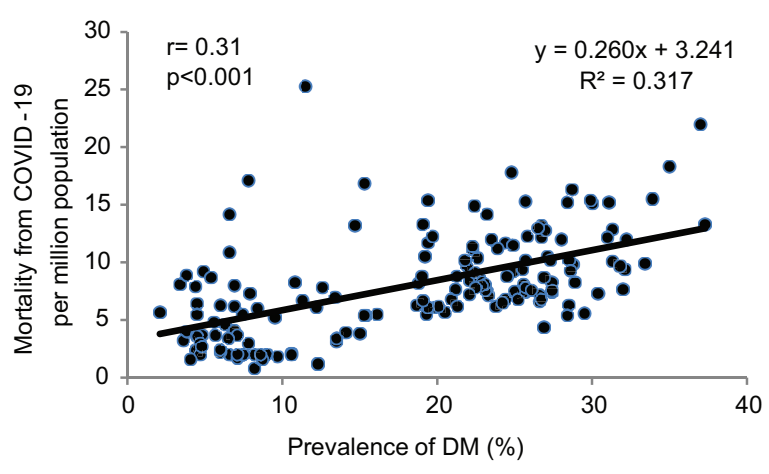

Fig. 1 (a)

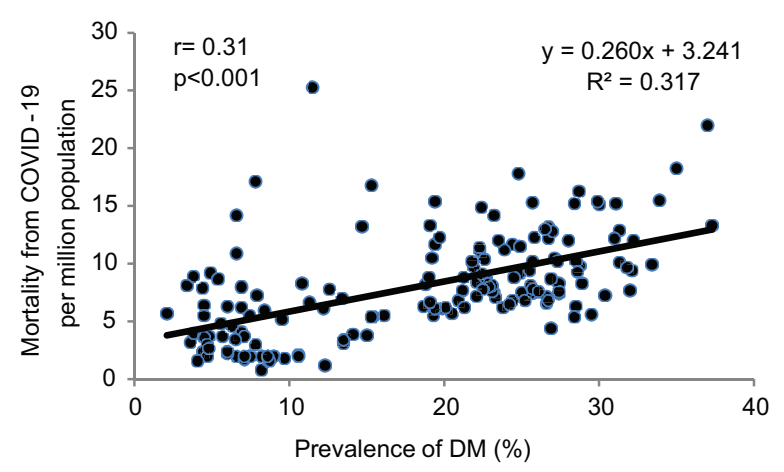

Fig. 1 (b)

Fig.-1: Correlation curve between mortality from COVID-19 per million general populations with prevalence of obesity (1a) and prevalence of DM (1b)

1. Emergency medical officer, Kurmitola general hospital, Cantonment, Dhaka-1206, Bangladesh.

2. Assistant professor, Department of Endocrinology, Mugda medical college hospital, Dhaka, Bangladesh.

3. Junior consultant, Medicine, Jinjira 20 beded hospital, Keranigonj, Dhaka, Bangladesh.

Address of Correspondence: Dr. Md. Shahed Morshed, Emergency medical officer, Kurmitola general hospital, Cantonment, Dhaka-1206, Bangladesh.Phone: +88 01738-842019, email: shahedk62@gmail.com 
confidence interval of $\mathrm{B}=-1.33,11.69$; $\mathrm{a}=0.12, \mathrm{p}=$ 0.12). According to the source, the cut off value to define obesity was $30 \mathrm{~kg} / \mathrm{m}^{2}$ and Bangladesh had only $3.4 \%$ obese people in 2016. But we know that the cut off point for Asian is $25 \mathrm{~kg} / \mathrm{m}^{2} .{ }^{7}$ Because of the economic transition, the prevalence of obesity is increasing in both adults and children. During this COVID-19 pandemic, physical activities are reduced. This may further increase the incidence of obesity rapidly. We are uncertain about how long the COVID19 situation will persist. So, obesity should be well addressed to avoid the health hazards. As people are using different types of social media much more these days, so awareness regarding healthy lifestyles including food habits and home based exercises can be built up by government and different medical professional societies. Hospitals should take a step to measure height and weight of every patient during admission. COVID-19 patients with obesity should get extra attention from the time of admission too.

\section{References:}

1. Islam QT, Hossain HT, Fahim FR, et al. Clinicodemograhic profile, treatment outline and clinical outcome of 236 confirmed hospitalized covid- 19 patients: a multi-centered descriptive study in dhaka,
Bangladesh. BJM 2020;31(2):52-57. DOI: https:// doi.org/ 10.3329/bjm.v31i2.48532

2. Popkin BM, Du S, Green WD, MA et al. Individuals with obesity and COVID-19: A global perspective on the epidemiology and biological relationships. Obesity Rev 2020. https://doi.org/10.1111/obr.13128

3. Hussain A, Mahawar K, Xia Z, Yang W, Shamsi EH. Obesity and mortality of COVID-19: meta-analysis. Obesity res clin pract 2020. doi: 10.1016/ j.orcp.2020.07.002

4. World health organization. WHO coronavirus disease (COVID-19) dash board. 10:26 am CEST, 9 September 2020. Available at: https://covid19.who.int/table.

5. World health organization. Prevalence of obesity among adults, BMI e" 30 (crude estimate) (\%). Last updated 22 September 2017. Available at: https:// www.who.int/data/gho/data/indicators/indicatordetails/GHO/prevalence-of-obesity-among-adults-bmi$=-30-($ crude-estimate) $-(-)$

6. International diabetes federation. IDF Diabetes Atlas, $9^{\text {th }}$ edition, Brussels, Belgium 2019. https:// www.diabetesatlas.org.

7. World Health Organization. The Asia-Pacific perspective: redefining obesity and its treatment. Australia: Health Communication 2000. https:// apps.who.int/iris/handle/10665/206936. 